\title{
Gold shunt for refractory advanced low-tension glaucoma with spared central acuity
}

This article was published in the following Dove Press journal:

International Medical Case Reports Journal

18 March 2016

Number of times this article has been viewed

\author{
Ryan Le' \\ Neeru Gupta ${ }^{1-3}$ \\ 'Keenan Research Center, Li Ka Shing \\ Knowledge Institute, St. Michael's \\ Hospital, Toronto, ON, Canada; \\ ${ }^{2}$ Ophthalmology and Vision Sciences, \\ Glaucoma Unit, St. Michael's Hospital, \\ University of Toronto, Toronto, ON, \\ Canada; ${ }^{3}$ Laboratory Medicine and \\ Pathobiology, St. Michael's Hospital, \\ University of Toronto, Toronto, ON, \\ Canada
}

\begin{abstract}
The aim of this study is to report a case of gold shunt surgery for uncontrolled, low-tension glaucoma with good central vision, after having a previously failed trabeculectomy and tube shunt surgeries. The patient was receiving maximum medical glaucoma therapy of four different types with intraocular pressure of $17 \mathrm{~mm} \mathrm{Hg}$ prior to gold shunt surgery. Five years later, intraocular pressure is well controlled in the low teens without the need for ocular medications, and glaucoma is stable following gold shunt surgery.
\end{abstract}

Keywords: gold shunt, refractory glaucoma, glaucoma surgery, trabeculectomy, suprachoroidal space, tube shunt

\section{Introduction}

Glaucoma is treated initially with medical therapy or laser procedures. For patients who are unresponsive, surgical treatments may be necessary, and traditionally these include trabeculectomy and tube shunts. If these procedures fail, options to decrease intraocular pressure (IOP) are limited, and either repeat filtering surgery or cyclophotocoagulation can be considered. Common filtering procedures such as trabeculectomy and tube shunts lower IOP by shunting aqueous humor from the anterior chamber of the eye to the subconjunctival space. Unlike these methods, the gold shunt exploits an alternate pathway, shunting fluid from the anterior chamber directly into the suprachoroidal space. The gold shunt is a glaucoma drainage implant made of $99.95 \%$ gold, measuring $6 \mathrm{~mm}$ by $3.5 \mathrm{~mm}$ by $0.12 \mathrm{~mm}$, and contains a series of channels to allow for fluid shunting from the anterior chamber. The head of the device is placed in the anterior chamber with the tail placed into the suprachoroidal space. Drainage through this route is possible due to a hydrostatic pressure gradient between these compartments. ${ }^{1,2}$ The gold shunt has only been approved for use in certain European countries since 2005. Health Canada approved gold shunt use in 2009, and in the United States the gold shunt is currently under Phase III clinical trials. Here, we report a unique case of gold shunt surgery with long-term follow-up in a challenging patient with refractory, advanced, low-tension glaucoma, at risk of losing remaining central vision after multiple failed filtration surgeries previously.

\section{Case report}

A 50-year-old male electrical engineer was referred to the glaucoma unit at St. Michael's Hospital on October 20, 2010, for left uncontrolled low-tension glaucoma on maximum medical therapy. His past ocular history included a right eye trabeculectomy, followed by a right Ahmed valve placement and right cataract extraction with lens implantation in 


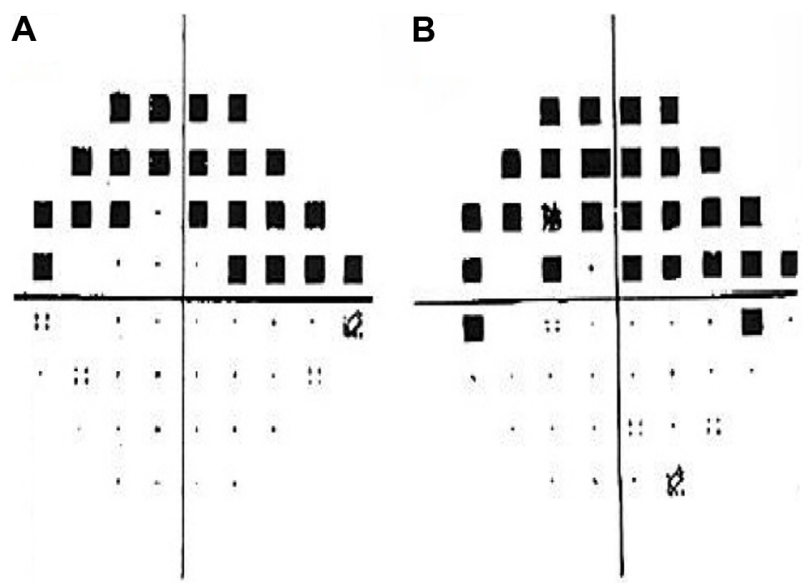

Figure I In 2008, Humphrey visual fields show left dense superior field loss with MD of $-12.37 \mathrm{~dB}(\mathrm{~A})$ and in 2010 , progressive field loss with $\mathrm{MD}-14.25 \mathrm{~dB}$ threatening fixation is noted $(\mathbf{B})$.

Abbreviation: MD, mean deviation.

2006. In the left eye, a left Ahmed valve was placed in 2007. A diagnosis of low-tension glaucoma had been previously established by the referring glaucoma specialist. The patient had progressive visual field loss despite IOP in the teens, with multiple failed filtration surgeries. He was highly myopic at $-14.00 \mathrm{D}$ in each eye. His family history was negative for glaucoma, and he had a history of remote inhaled steroid use of several months duration. Past medical history included a resolved tuberculosis infection 16 years earlier.

At the time of his visit, he was using brinzolamide 1\% tid OU, brimonidine bid OU, timolol $0.5 \%$ once am OU, and bimatoprost $0.01 \%$ at hs OU. On examination, hand vitiligo was noted. Best corrected visual acuity was 20/30 OD and 20/40 OS and IOPs were $12 \mathrm{mmHg}$ OD and $16 \mathrm{mmHg}$ OS at $12: 35 \mathrm{pm}$. Ocular motility was full, and pupils were equally reactive to light with no afferent pupillary defect. There was marked injection of the inferior lid margins and conjunctiva. Corneal thicknesses were 574 and $576 \mu \mathrm{m}$ in the right and left eyes, respectively. The right anterior chamber showed a tube entering at the 11 o'clock position and the left anterior chamber showed a tube entering at the 4 o'clock position in the presence of iridotomies superiorly. Angles were wide open, and right posterior chamber intraocular lens was in good position. Early nuclear sclerosis was seen in the left eye. Right optic nerve head revealed severe cupping, and the left optic nerve revealed a 0.8 cup with superonasal neuroretinal rim remaining. Shallow excavation was noted in both eyes. Large temporal zones of beta parapapillary atrophy were also noted. Visual field tests showed right superior hemifield loss splitting fixation and left superior arcuate changes approaching fixation. Left visual field progression over 2 years was documented (Figure 1A and B).

In view of uncontrolled, end-stage, low-tension glaucoma with advanced progressive field loss and IOP in high teens on maximal medical therapy, the options of trabeculectomy with or without cataract extraction and intraocular lens implantation were discussed in detail with the patient. After discussing the benefits and risks of the procedure, the patient elected to proceed with combined left trabeculectomy, cataract extraction, and intraocular lens implantation with mitomycin C. The surgery was performed on November 30, 2010. Several weeks after the surgery, he underwent bleb needling due to rapid scarring and remained uncontrolled despite reinstituting maximal medical therapy. The option of gold shunt surgery was discussed to bypass conjunctival scarring issues, including the benefits and risks, and the patient elected to proceed with gold shunt surgery.

On February 22, 2011, left uncomplicated gold shunt surgery was performed. On the first day after the surgery, best corrected visual acuity was 20/200 OS, IOP measured $6 \mathrm{mmHg}$ OS at 4:20 pm, with trace anterior chamber reaction. He was treated with ofloxacin qid and prednisolone $1 \%$ qh for 5 weeks. Left eye visual acuity improved, and IOP remained low over the first 3 months. On July 13, 2011, best corrected visual
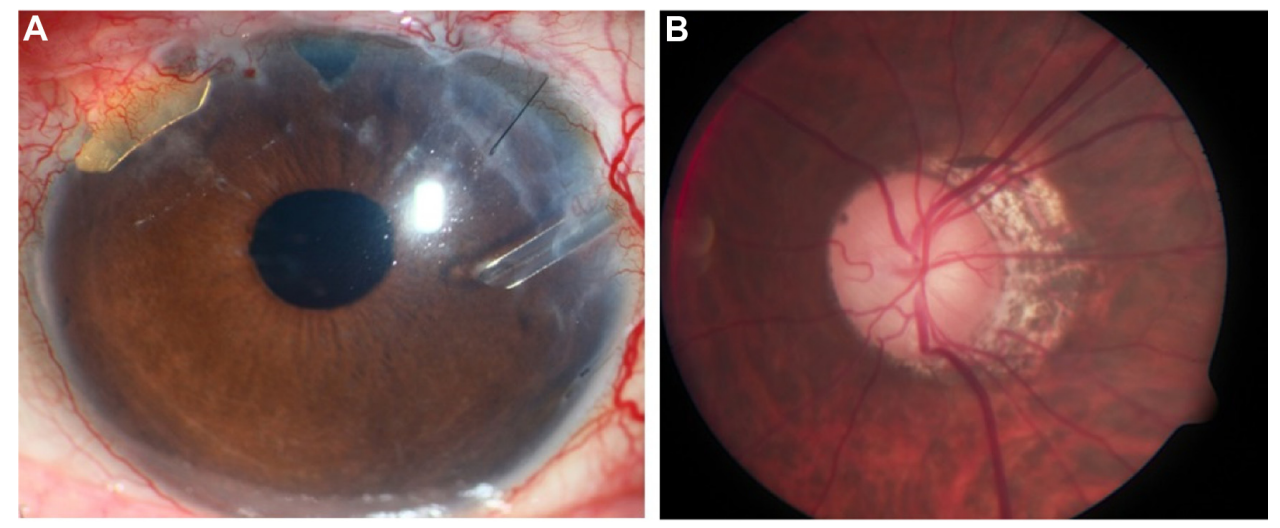

Figure 2 Four months following surgery, left eye anterior segment shows gold shunt in the superonasal quadrant in good position (A), with advanced cupping in a highly myopic left optic nerve (B). 


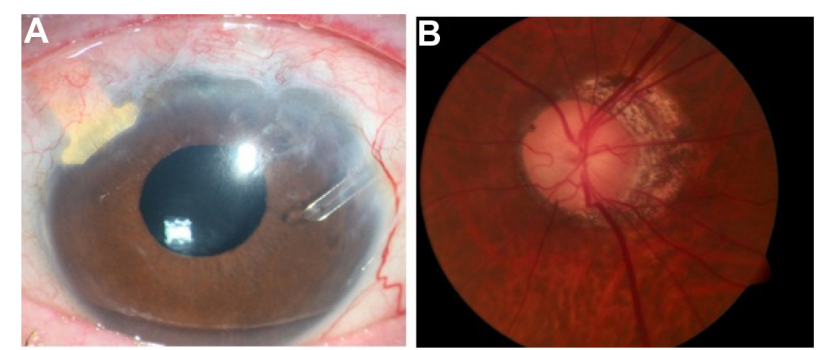

Figure 3 Four years following surgery, left eye anterior segment with gold shunt in good position (A), with stable glaucomatous optic neuropathy (B).

acuity was 20/20 OD and 20/30+2 OS. Intraocular pressures remained mostly in the low teens, using two glaucoma medications in the right eye only. The gold shunt remained in good position and glaucoma appeared stable (Figure $2 \mathrm{~A}$ and $\mathrm{B}$ ). Over a 5-year follow-up period, visual acuity

A

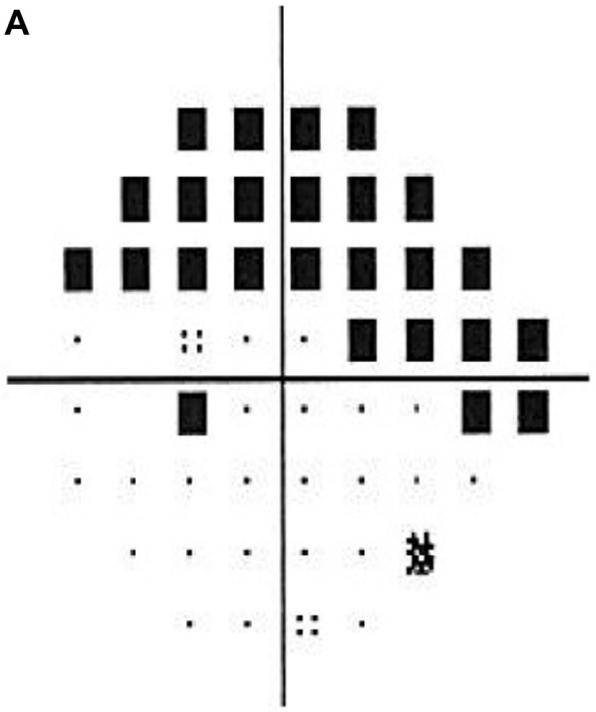

C

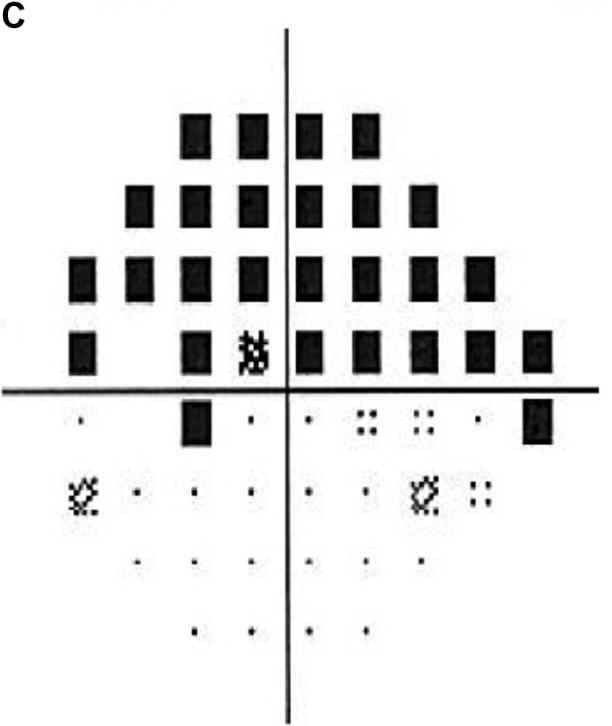

(VA), IOPs, and glaucoma remained stable. On May 27, 2015, best corrected visual acuity was 20/30+2 OD, 20/25-2 OS, and IOP measured $14 \mathrm{mmHg} O U$ at 11:35 am, with no changes in medication. The gold shunt continued to be in good position, and glaucomatous optic neuropathy remained stable (Figure 3A and B). Visual fields remained stable throughout the period of follow-up (Figure 4A-D). At his last visit on October 26, 2015, IOP measured $10 \mathrm{mmHg}$ OU and $12 \mathrm{mmHg}$ OS, with no changes in medication. St. Michael's Hospital Research Ethics Board approval was obtained for this case report, and the patient provided written informed consent.

\section{Discussion}

In this challenging case of a young gentleman with low-tension glaucoma, advanced visual field loss, and history of multiple

B

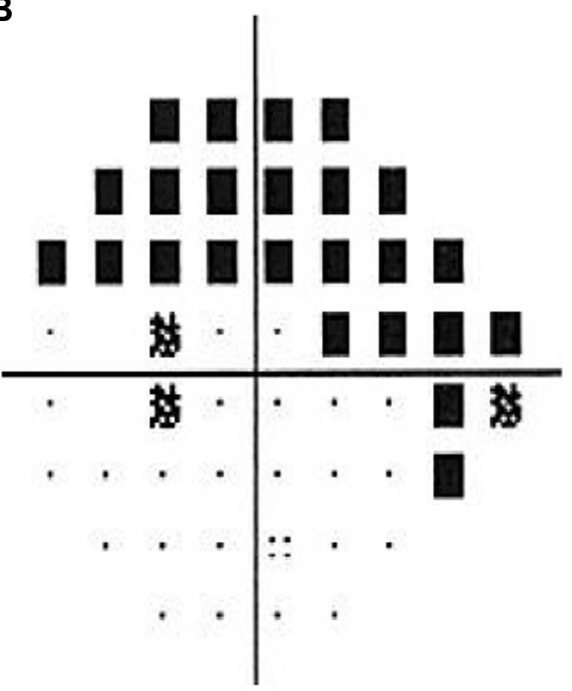

D

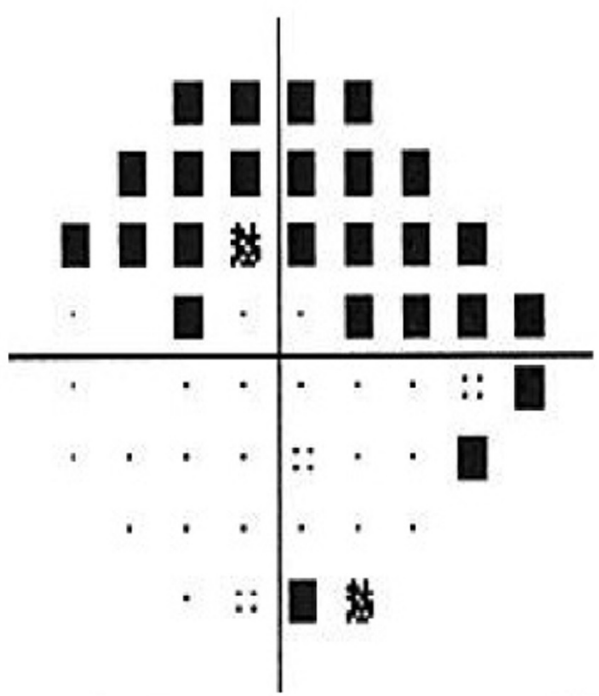

Figure 4 Humphrey visual fields show stable left visual fields following gold shunt surgery with MD of $-1 \mathrm{I} .84 \mathrm{~dB}$ at I.5 years later (A), $-12.21 \mathrm{~dB}$ at 2.5 years later (B), -14.20 $\mathrm{dB}$ at 3.5 years later $(\mathbf{C})$, and $-13.1 \mathrm{I} \mathrm{dB}$ at 4.5 years later (D). 
failed glaucoma filtering procedures, the gold shunt effectively reduced IOP without need for glaucoma medications, over 5 years. The efficacy and complication rate between standard surgical interventions, such as trabeculectomy and tube shunts, are similar at $68 \%$ and $70 \%$, respectively, at 4 years. $^{3-5}$ Glaucoma care is significantly challenged when either of these procedures fail and particularly in patients with good visual potential. In these cases, repeat filtering surgery is typically considered.

In adults with an initial failed procedure, information on the success rate of a second filtration surgery is limited. In pediatric populations, however, repeat procedures of either type after failed trabeculectomy report success rates of $69 \%$ and $64 \%$ for trabeculectomy and Ahmed valve placement, respectively. ${ }^{6}$ Cyclophotocoagulation is indicated for patients with refractory glaucoma and limited visual potential due to higher risks of suprachoroid hemorrhage and hypotony. ${ }^{7-9}$ Sequential tube shunt success is reported to range from $62 \%$ to $75 \%$, similar to cyclophotocoagulation success rates of $66 \%$. Placement of a second tube shunt after primary tube failure has a low reported success rate of $40 \%{ }^{10}$

Gold shunt surgery is generally reserved for patients with low visual potential and has success rates ranging from $67 \%$ to $79 \%{ }^{11,12}$, comparable to that of Ahmed valves. ${ }^{13}$ Shunt failure and complications may be due to a variety of factors, including shunt fibrosis possibly from cytokines, varying surgical techniques, and use of older gold shunt models. ${ }^{14-17}$ This patient continues to be well controlled 5 years after gold shunt surgery. After previous failed traditional filtration surgeries, the option of gold shunt in the suprachoroidal space may also be considered for patients needing lower IOP in the presence of good central vision.

\section{Disclosure}

The authors report no conflicts of interest in this work. Gold shunts were provided by SOLX to St. Michael's Hospital for compassionate use.

\section{References}

1. Francis BA, Singh K, Lin SC, et al. Novel glaucoma procedures: a report by the American Academy of Ophthalmology. Ophthalmology. 2011;118(7):1466-1480.

International Medical Case Reports Journal

\section{Publish your work in this journal}

The International Medical Case Reports Journal is an international, peer-reviewed open-access journal publishing original case reports from all medical specialties. Previously unpublished medical posters are also accepted relating to any area of clinical or preclinical science. Submissions should not normally exceed 2,000 words or
2. Emi K, Pederson JE, Toris CB. Hydrostatic pressure of the suprachoroidal space. Invest Ophthalmol Vis Sci. 1989;30(2):233-238.

3. HaiBo T, Xin K, ShiHeng L, Lin L. Comparison of Ahmed glaucoma valve implantation and trabeculectomy for glaucoma: a systematic review and meta-analysis. PLoS One. 2015;10(2):e0118142.

4. Wilson MR, Mendis U, Paliwal A, Haynatzka V. Long-term follow-up of primary glaucoma surgery with Ahmed glaucoma valve implant versus trabeculectomy. Am J Ophthalmol. 2003;136(3):464-470.

5. Wilson MR, Mendis U, Smith SD, Paliwal A. Ahmed glaucoma valve implant vs trabeculectomy in the surgical treatment of glaucoma: a randomized clinical trial. Am J Ophthalmol. 2000;130(3):267-273.

6. Lee N, Ma KT, Bae HW, et al. Surgical results of trabeculectomy and Ahmed valve implantation following a previous failed trabeculectomy in primary congenital glaucoma patients. Korean J Ophthalmol. 2015;29(2):109-114.

7. Gupta N, Weinreb RN. Diode laser transscleral cyclophotocoagulation. J Glaucoma. 1997;6(6):426-429.

8. Sood S, Beck AD. Cyclophotocoagulation versus sequential tube shunt as a secondary intervention following primary tube shunt failure in pediatric glaucoma. J AAPOS. 2009;13(4):379-383.

9. Shah AA, WuDunn D, Cantor LB. Shunt revision versus additional tube shunt implantation after failed tube shunt surgery in refractory glaucoma. Am J Ophthalmol. 2000;129(4):455-460.

10. Schaefer, JL, Levine MA, Martorana G, Koenigsman H, Smith MF, Sherwood MB. Failed glaucoma drainage implant: long-term outcomes of a second glaucoma drainage device versus cyclophotocoagulation. Br J Ophthalmol. 2015;99(12):1718-1724.

11. Figus M, Lazzeri S, Fogagnolo P, Iester M, Martinelli P, Nardi M. Supracilliary shunt in refractory glaucoma. $\mathrm{Br} J$ Ophthalmol. 2011;95(11):1537-1541.

12. Melamed S, Ben Simon GJ, Goldenfeld M, Simon G. Efficacy and safety of gold micro shunt implantation to the supraciliary space in patients with glaucoma: a pilot study. Arch Ophthalmol. 2009;127(3):264-269.

13. Skaat A, Sagiv O, Kinori M, Simon GJ, Goldenfeld M, Melamed S. Gold micro-shunt implants versus Ahmed glaucoma valve: long-term outcomes of a prospective randomized clinical trial. J Glaucoma. Epub October 14, 2014.

14. Hueber A, Roters S, Jordan JF, Konen W. Retrospective analysis of the success and safety of Gold Micro Shunt Implantation in glaucoma. BMC Ophthalmol. 2013;13:35.

15. Rekas M, Pawlik B, Grala B, Kozlowski W. Clinical and morphological evaluation of gold micro shunt after unsuccessful surgical treatment of patients with primary open-angle glaucoma. Eye (Lond). 2013;27(10):1214-1217.

16. Berk TA, Tam DY, Werner L, Mamalis N, Ahmed II. Electron microscopic evaluation of gold glaucoma micro shunt after explantation. J Cataract Refract Surg. 2015;41(3):674-680.

17. Agnifili L, Costagliola C, Figus M, et al. Histological findings of failed gold micro shunts in primary open-angle glaucoma. Graefes Arch Clin Exp Ophthalmol. 2012;250(1):143-149.
4 published pages including figures, diagrams and references. The manuscript management system is completely online and includes a very quick and fair peer-review system, which is all easy to use. Visit $\mathrm{http}: / /$ www.dovepress.com/testimonials.php to read real quotes from published authors. 